\title{
TEXTOS Y COMENTARIOS DE CUATRO RELATOS BOCOTAS REFERENTES A CATACLISMOS
}

\author{
Enrique Margery Peña
}

\begin{abstract}
The author presents four cataclysmal narratives in the Chiriqui dialect of Bocota. The narratives deal with the myths of the great deluge, the long night, the great earthquake and the great starvation. Each narrative is presented in its Bocotá version followed by a word-by-word translation and a free translation. The author's comments relate the content of these myths to similar ones in the oral Amerindian tradition. A list of the motives developed in these narratives is given, following Stith Thompson's Motif-Index.
\end{abstract}

\section{Preliminares}

En el curso de nuestra recopilación de materiales de la tradición oral del bocotá de Chiriquí, obtuvimos cuatro textos enmarcados en la temática de la cataclismología. Los textos en referencia corresponden a los relatos Júli ke kíru suadáble Chubé nô ('El cataclismo que Chubé le anunció a Júli'); Chuí chará drebadáble ñiảin ('Cuando se apagó la luz del sol en los primeros tiempos'); Koróyi Tóndo Mési Tóndo ('Koróyi Tóndo y Mési Tóndo'), y Bogá Dadiá Nuí Dadiá ('Bogá Dadiá y Nuí Dadiá').

En la perspectiva de la temática cataclismológica, estos relatos corresponden, respectivamente, a la gran inundación, la larga noche, el gran temblor y la gran hambruna.

\subsection{Fuente de los relatos}

$\mathrm{Al}$ igual que el conjunto de narraciones del bocotá de Chiriquí que hasta la fecha hemos recopilado, estos cuatro relatos nos fueron proporcionados por nuestro informante, don Francisco Rodríguez Atencio. El señor Rodríguez nació en 1935 en el distrito de San Félix de la Provincia de Chiriquí, en la República de Panamá, lugar del que emigró en 1980 para establecerse en el localidad de Coto Brus, en el extremo sur del territorio de Costa Rica, donde reside en la actualidad dedicado a labores de agricultura y a su oficio de sastre.

\subsection{Presentación de los relatos}

Cada texto se ofrece en su versión en bocotá - transcrita en un alfabeto práctico cuyos fundamentos y equivalencias hemos expuesto en anteriores trabajos ${ }^{1}$ - seguida de una traducción palabra a palabra, y luego de una versión libre en español.

En los textos en alfabeto práctico se emplean comas para la notación de pausas breves, y puntos para la notación de pausas más extensas registradas en el relato del 
informante. Además, se usan mayúsculas para los encabezados de enunciados después de un punto, así como en los casos del grafema inicial de los nombres propios. Cabe también señalar que en los textos en bocotá aparecen entre paréntesis los números que se corresponden con los de la traducción palabra a palabra que sigue a cada relato transcrito en alfabeto práctico.

En lo que respecta a las traducciones palabra a palabra, conviene precisar que los significados de algunos elementos, especialmente sufijos, se dan de manera tentativa y sujetos a posteriores verificaciones, en tanto corresponden al estado actual de nuestras investigaciones sobre la morfología del bocotá de Chiriquí. En estas traducciones se emplean guiones $(-)$ pospuestos al significado del radical o de la forma base, para las denotaciones de sufijos, y el signo "+" en los casos del significado de términos que en su traducción al español requieren de dos o más lexemas. Conviene aquí hacer notar que en las traducciones palabra a palabra hemos acudido a algunas abreviaturas cliyas correspondencias son las siguientes:

$\begin{array}{rlrl}\text { adj } & =\text { 'adjetivador' } & \text { ind } & =\text { 'voz indefinida' } \\ \text { adv } & =\text { 'adverbializador' int }=\text { 'intensificador' } \\ \text { ag } & =\text { 'agentivo' } & \text { irr } & =\text { 'perfecto irremo- } \\ \text { cond }=\text { 'condicional' } & & \text { tospectivo' } \\ \text { dat }=\text { 'dativo' } & \text { obl }=\text { 'obligativo' } \\ \text { des }=\text { 'desiderativo' } & \mathrm{pl}=\text { 'pluralizador' } \\ \text { dir }=\text { 'direccional' } & \text { pos }=\text { 'posesivo' } \\ \text { fut }=\text { 'futuro' } & \text { rec }=\text { 'reciproco' } \\ \text { gen }=\text { 'genitivo' } & \text { refl }=\text { 'reflejo' } \\ \text { imp }=\text { 'imperfecto' } & \text { rem }=\text { 'perfecto remotos- } \\ & & & \text { pectivo' }\end{array}$

Por último, en lo que guarda relación con las notas cabe señalar que las versiones en bocotá contienen aquellas que son pertinentes a aspectos propiamente lingüísticos, en tanto que en las traducciones libres se han colocado las notas referentes tanto a los contenidos de los relatos como a determinadas acotaciones etnográficas que hemos creido necesario registrar.

\section{Textos}

\section{1. (1) Júli² $\mathrm{ke}^{3} \mathrm{kíru}^{4}$ suadáble Chubé no}

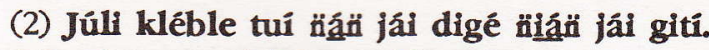

(3) Ché tóu kê begáble ché tóule. (4) Giráwa ché joyáble nansére, (5) môni ñạmbége, (6) móï bué miantainwále. (7) Amåăt kóde Chubé no táble, (8) chá be kuăin ${ }^{5}$ éde jinạnde tiậin dabá digé. (9) Chá be bége monsóle kiru suáde bitigă ${ }^{6}$ ge. (10) káre Júli kléble tuí úle muíre gulé, (11) kiruá7 no kléble, (12) jiáa no kléble tuí ó gulé. (13) Âmẩ lini mổỉ iá nô Júli jăi kíru begáble 8 ta líh ge. (14) Kuáth bitigá mị iále joyáble bége ta lín ge. (15) Degéble no chá glé môni muiânde bá9 muiănde, (16) kuạndre muiạnde glé chá no. (17) Blé be chigé, dabá jâi be kanẹenñămă degéble Chubé no chá ge. (18) Ammạin kóde bá nô chá kíru begá ta linin ge, kléble degéde bitigá ge. (19) Giráwa bitigá ke joyáble mị̈ wåle wạle klé ché óde, (20) wălle kiru dodáde wạlle degêble, degé klêble bitigá no ke. (21) Kiru jái suáda kléble iá segé no, jundá segé no, künúti segé no. (22) Kíru julíta segé kléble kiru suáde, (23) giráwa kuáh̆ mịn iále bége ta liñ ge. (24) Degéble no kiru kuéri bigébi chigéga ché ge. (25) Âmạin kóde bá no jundá sribáda, (26) bá nọ iá sribáda, (27) kunnúü sribáda bá no, (28) juaíĭ sribáda káre juyugá jăi digé. (29) Jái batágli kỉru chá glê suáde bá ge. (30) Giráwa bá ne chá kíru begá ta lịin ge, chá glé degéde bá ge. (31) Bá minì iále chá kíru bége ta lini ge. (32) Amạại kóde ñẩỉ be jẹmlé suáli. (33) Chuí ơngố digé blé be chigé ïạain jăi digé, degéble no. (34) Káre kuáñ no buáble yé miantañuwạlle, (35) iá jải yé mạni káre kléble bué juyugá de kuéri digé. (36) Giti joyáble sídre, (37) giráwa jái ñẹru gulé, glibada kegáble no, (38) gisega giti du kảre biảle káre. (39) Gíti Chubé nê blidáble nún̈ wágaba segé. (40) Jải segé degéble Chubé no ke. (41) Bá no yé miantäniwậle bá mọin 
iá gabáde andalẩi gadáde, (42) bá no begá sidre du segé bá gulé. (43) Nạin be jẹmlé dái gadáde. (44) Kuát be jonétitiama julita. (45) Yé miantainwạlle be jonéningama julíta, degéble no. (46) Júli jải káre kléble suáde bitigá ge, (47) giráwa bitigá minin wâlle gití kiru mịni iảle kíru begáble ta lịin ge. (48) Anamạñ digé joyáble juyugá kuéri digé yé julíta bué, (49) kléble móñ báte, (50) kléble kunưun bué, (51) klēble iá jải bué, (52) kléble yé miantañwále bué. (53) Giráwa Júli jăi chigêble kiru yúge kâre. (54) Du jải joyáble biåle. (55) Âmånin giti degéble nô chuí ởigé digé kiru be chigéga mônï muiănde dále. (56) Bá nô mônï joléceñkabe mônï báde, (57) móñ̄. bué miantåñ wa le joyáble bitigá muiănde. (58) Bitigá joyáble jolêñ kabe gídáde. (59) Âmạañ gíti chuí ơngó digé tiạin gadáde. (60) Gídi chuí ongeó digé chigebléga siáru, iảru, janigáru, yanigáru blê chigéble. (61) Gíti wiámble bitigá no, (62) giráwa Júli jải joyablébi du segéru. (63) Yé miantạañạale tegablébi biále ñạnin segéru no. (64) Giti joyáble niạin segéru nå jugá jegáble no. (65) Giti blé chigéble joyảble. (66) Chigéga blé giti nânia. (67) Badágli bitigá no degéble, (68) Hẹêtige bró chá be bá bége ta linin ge, (69) bái chá juétỉ káre, (70) kiráwa joyablébi chigéga blé. (71) Giti suáli joyáble jobéga blé gití nạmándige, (72) jonembléga,

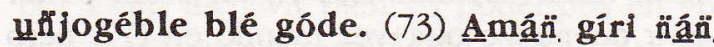
chebegéble julire dái gadáde. (74) Giti Júli jăi Chubé chigéble bledále ó gulé. (75) Degéble no ñảỉ chigé monó, (76) gíti chá be bá bége tuí ne kogobéne thẩi segé. (77) Giráwa chá be bá tôu jái blite iu, (78) chá be bége bá tóule. (79) Ammảit kóde bá be tuí nú môiỉ bitigá gulé, degéble no. (80) Giti judéñ ${ }^{10}$ kegáble n̈ânin. mịndu segé Júli no Chubé gulé. (81) Judén̈ chigéble jolêeinkabe kuánin jabá kléble suáli, (82) dabá ñâni kléble éru. (83) Sigidéble dabá segé, (84) sarágada jogéble jiendéga dibí segé, (85) Jogebléga kléble kuáni gúde, gudáble nọ (86) Chugá kliáble kuáhi jabá segé no (87) Amạă kóde chugá dábe ché jải biá kóde. (88) Joyáble Chubé nạmândige. (89) Doanandáble

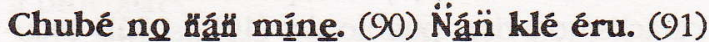
Minyebále bá chugá jine, bá sarágata jine. (92) Mi̊̃. degéble no (93) Gíti bodregá kagáble no. (94) Bodregá chigéble jollétikabe blidéga blé digé, (95) jogêble móoin wiéñgiti, (96) mịi kiru duáble no. (97) Giti biúsi kagáble no. (98) Biúsi chigéble

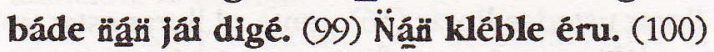
Biúsi miantañwậle jalini kuéri chigéble ñậi mindu giti. (101) Sarágata joyáble jiendéga dibi segé, (102) ché biá klêble dibí gulé. (103) Ámánỉ kóde biúsi sarágata dábe kăre. (104) Gíti jogeblénị. (105) Kuabága dále biúsi kagáble kogobéne. (106) Degéble biúsỉ ge Chubé no, (107) bá jogá gliá chigébi - tiậi unmạñ. (108) Bá no gliá idá gáde, (109) bá chigé dué chá ge miânio dảle chá ge. (110) káre biúsi chigéble kuabága dále, (111) jogéble gliá dué. (112) Chubé no degéble, ñạiñ joyibi tuí gadá bá ge Júli ge. (113) Káre Júli begâble tui ñânị jải digé. (114) Ámanạă digé ché glé jâre. (115) Blé kuéri ché kånạmbléga, (116) åmạin kóde ché glé monạnde. (117) Jăi gíri degéble Chubé no ke, (118) bá no mốti dagiáde, (119) bá no mịii kíru buá nansére. (120) Kuáñ ñếru neêru chá no känglệïga. (121) Jăi káre chá be bué mổin dige káre. (122) Bá mónin dagiáde uliá tịnkle äạin jegabále dabá. (123) Kiru mịne mine wiâle julita chá ge. (124) Amáái kóde bá be tuí nưini, chá gibiá segé, chá kirảia gití, chá ụï gití. (125) Bá tuí nụio. bá bitigá gulé, bá girógro gulé

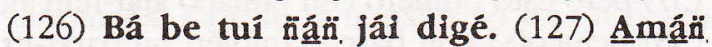
kóde ché glé jăre monạande ñạain dabá digé. (128) Jải batágli.

(1) Júlí dat cataclismo avisar-rem Chubé ag (2) Júli estar-rem vivir mundo este en comienzo este sobre (3) nosotros diente(s) piedra poner-rem nosotros diente(s)-adj (4) pero nosotros llegar-rem malos (5) rec matar (6) rec hacer de+todas+clases (7) eso por Chubé 
pensar-rem (8) yo fut hombre uno buscar mundo tierra en (9) yo fut poner el+que+avisa cataclismo avisar pueblo dat (10) así Júli estarrem vivir junto-adv mujer con (11) hijo(s) gen estar-rem (12) hija(s) gen estar-rem vivir él con (13) ese solo refl int ag Júli este aviso poner+atención querer para dat (14) gente pueblo no nothaber llegar poner+atención querer para dat (15) decir-rem ag yo estar refl llorar ustedes llorar (16) gente-pl llorar estar yo ag (17) mar fut venir tierra esta fut terminar decir-rem Chubé ag yo dat (18) eso por ustedes ag yo aviso poner+atención querer para dat estar-rem decir pueblo dat (19) pero pueblo dat llegar-rem no nada nada estar nosotros engañar (20) nada cataclismo ocurrir nada decir-rem decir estar-rem pueblo ag dat (21) cataclismo este avisar estar-rem chichada en peonada en balsería en ag (22) noticia todos en estar-rem cataclismo avisar (23) pero gente no nothaber poner+atención querer para dat (24) decir-rem ag cataclismo grande resultar-ya venir-dir nosotros dat (25) eso por ustedes peonada hacer (26) ustedes ag chichada hacer (27) balsería hacer ustedes ag (28) ceremonia+ de+la+claridad hacer también cerro este en (29) este último aviso yo estar avisar ustedes dat (30) pero ustedes ag yo aviso poner+atención querer para dat yo estar decir ustedes dat (31) ustedes no nothaber yo aviso poner+atención querer apra dat (32) eso por mundo fut perder mañana (33) sol en+la+tarde en mar fut venir tierra esta en decir-rem ag (34) así gente ag hacer-rem cosa(s) de+todas+clases (35) chichada esta cosa qué también estar-rem hacer cerro junto grande en (36) entonces llegar-rem también (37) pero esto primero con rama(s) atar-rem ag (38) bejuco(s) con barco también preparar-irr así (39) entonces Chubé ag transformar-rem bonito ojo(s) en (40) esto en decir-rem Chubé ag dat (41) usted ag animal(es) de+todas+clases usted refl int hembra macho uno+y+uno (42) usted ag poner también barco dentro usted con (43) mundo fut desaparecer luna una (44) gente fut acabar toda (45) cosa(s) de+todas+clases fut acabarse todas decir-rem ag (46) Júli este así estar-rem avisar pueblo dat (47) pero pueblo no nada en cataclismo no no+haber noticia poner+atención-rem querer para dat (48) eso en llegar-rem cerro grande en cosa(s) todas hacer (49) estar-rem rec golpear (50) estar-rem balsería hacer (51) estar-rem chichada esta hacer (52) estar-rem cosa(s) de+todas+clases hacer (53) pero Júli este venir-rem noticia oir también (54) barco este llegar-rem preparar-adj (55) eso entonces decir-rem ag sol en+la+tarde en cataclismo fut venir-dir ustedes llorar para (56) ustedes ag rec nada+más rec golpear (57) rec hacer de+todas+clases llegar-rem familia llorar (58) pueblo llegar-rem nada+más reir (59) eso entonces sol en $+\mathrm{la}+$ tarde tierra sonar $(60)$ entonces sol en+la+tarde en venir-rem-dir este oeste sur norte mar venir-rem (61) entonces saber-rem pueblo ag (62) pero Júli este llegar-rem-ya barco dentro (63) cosa(s) de+todas+clases echar-rem-ya preparar-adj lugar dentro ag (64) entonces llegar-rem lugar dentro otra+vez puerta cerrar-rem ag (65) entonces mar venir-rem llegar-rem (66) venirdir mar en arriba (67) último pueblo ag decirrem (68) ahora sí yo fut usted poner+atención querer para dat (69) venga yo coger también (70) pero llegar-rem-ya venir-dir mar (71) entonces mitad llegar-rem nadar-dir mar sobre donde (72) desaparecer-rem-dir morir-rem mar por (73) eso después mundo quedar-rem triste luna una (74) entonces Júli este Chubé venirrem hablar-imp él con (75) decir-rem ag tierra venir dura (76) entonces yo fut usted poner vivir de+nuevo otra+vez mundo en (77) pero yo fut usted diente(s) estos cambiar maíz (78) yo fut poner usted diente(s)-adj (79) eso por usted fut vivir bien usted familia con decir-rem ag (80) entonces zopilote enviar-rem tierra ver en Júli ag Chubé con (81) zopilote venir-rem nada+más gente muerta estar-rem mitad (82) suelo lugar estar-rem suave (83) pisar-rem tierra en (84) pata(s) ir-rem hundir-dir suelo en (85) ir-rem-dir estar-rem gente comer comer-rem ag (86) cabeza meter-rem gente muerta dentro ag (87) eso por cabeza roja nosotros estos sangre por (88) llegar-rem Chubé donde (89) preguntar-rem Chubé ag mundo cómo (90) tierra estar suave (91) por+qué usted cabeza así usted pata(s) así (92) no decir-rem ag (93) 
entonces sapo enviar-rem ag (94) sapo venirrem nada+más orilla mar en (95) ir-rem refl por+el+mismo+camino (96) no noticia traerrem ag (97) entonces paloma enviar-rem ag (98) paloma venir-rem posarse tierra esta en (99) tierra estar-rem suave (100) paloma(s) $\mathrm{de}+$ todas +clases pequeña(s) grande(s) venirrem lugar verse-ind en (101) pata(s) llegar-rem hundir-dir suelo en (102) nosotros sangre estar-rem suelo con (103) eso por paloma(s) pata(s) roja(s) también (104) entonces ir-remotra+vez (105) cuatro+veces para paloma enviar otra+vez (106) decir-rem paloma dat Chubé ag (107) usted vaya hoja venir-ya o lugar rastrojo (108) usted ag hoja arrancar una (109) usted venir traer yo dat ver para yo dat (110) así paloma venir-rem cuatro+veces para (111) ir-rem hoja traer (112) Chubé ag decirrem tierra llegar+a+ser+ya vivir sobre usted dat Júli dat (113) así Júli poner-rem vivir tierra esta en (114) eso en nosotros estar aquí (115) mar grande nosotros terminar-rem-dir (116) eso por nosotros estar uno+a+uno (117) esto después decir-rem Chubé ag dat (118) ustedes ag rec querer (119) ustedes ag no hecho(s) hacer malos (120) gente primera primera yo ag terminar-irr-des (121) esto así yo fut hacer ustedes con también (122) ustedes rec querer contento(s) recto(s) lugar en+todas + partes-adv tierra (123) hecho(s) cómo cómo saber-imp todos yo dat (124) eso por usted fut vivir bien yo poder-pos en yo fuerza-pos en yo respiración en (125) usted vivir bien usted familia con usted hijos con (126) usted fut vivir mundo este en (127) eso por nosotros estar aquí uno+a+uno mundo tierra en (128) esto último.

\section{El cataclismo que Chubé le anunció a Júli}

Júli vivía en la tierra en los primeros tiempos de este mundo. Era el tiempo en que los hombres tenían los dientes de piedra. Sin embargo, por aquel entonces la gente había llegado a ser mala: se mataban y cometían toda clase de tropelías. Por eso Chubé pensó: "Elegiré en la tierra a un hombre, y él será quien avise a su pueblo el cataclismo que voy a provocar".

Y entonces, sólo a Júli, que vivía con su mujer y con sus hijos, Chubé le anunció que habría una gran inundación originada por la salida del mar.

Al recibir esta noticia, Jủli la comunicó a la gente de su pueblo, pero nadie le prestó atención. El les dijo:

- Estoy llorando por ustedes y por el resto de la gente. El mar todo lo va a inundar y con ello la tierra va a desaparecer.

Y les advirtió:

- Ustedes deben poner atención a lo que les estoy diciendo.

Pero la gente le respondió:

- No, nada va a ocurrir. Usted nos está engañando.

Sin embargo, Júli persistía en su intento de avisar a la gente el cataclismo que se avecinaba. Por eso iba a las chichadas, a las peonadas y a las balserías, adonde llegaba diciendo:

- Se avecina un cataclismo. Hagan peonadas, chichadas, balserías y ceremonias de la claridad $^{11}$ en el cerro. Este es el último aviso que les doy, aunque nadie quiere ponerme atención.

$Y$ terminaba diciendo:

- Chubé me ha dicho que muy pronto el mar se precipitará sobre la tierra.

Sin embargo, la gente siguió en sus cosas sin hacerle caso. Sólo les preocupaba una gran chichada que harían al pie del cerro. Júli pensaba ir también a esa chichada, pero antes hizo una embarcación de ramas atadas con bejucos. Y sucedió que cuando la embarcación estuvo terminada, Chubé la transformó en un barco grande y hermoso. Entonces Chubé le dijo a Júli:

- Ahora busque animales de todas clases; de cada especie coja una hembra y un macho, y póngalos con usted y con su familia dentro del barco. Sepa usted que mañana en la tarde se acabará la tierra y con ella toda la gente y todas las cosas.

Así le habló Chubé a Júli, y así fue éste a decírselo a la gente del pueblo, pero de nuevo nadie le prestó atención. Siguieron, al pie del 
cerro, golpeándose, participando en balserías, bebiendo en chichadas y haciendo toda clase de desmanes.

Júli, que ya había encerrado a los animales en el barco, dirigiéndose a todos, les dijo:

- Ustedes sólo se han dedicado a pelear y a cometer malas acciones. Por todo eso van a padecer ahora.

$\mathrm{Al}$ oir esto, todos se rieron.

Y ocurrió entonces que en la tarde del día siguiente el suelo comenzó a retumbar, y, luego, desde el este y el oeste, desde el sur y desde el norte, el mar se precipitó sobre la tierra.

Al momento todos se percataron del cataclismo, pero Juli ya estaba dentro del barco. El se había preparado poniendo toda clase de cosas en la embarcación, de modo que cuando vio venir el mar, cerró la puerta.

Entonces el mar lo inundó todo, y las aguas comenzaron a subir y subir. En medio de ellas, la gente gritaba mirando hacia el barco:

- ¡Desde ahora sí le prestaremos atención, pero, por favor, recójanos!

Pero ya era demasiado tarde. El mar seguía subiendo y ya todo lo había cubierto. Sólo la mitad de la gente pudo por algunos momentos mantenerse nadando desesperadamente antes de ser tragados por las aguas.

Después nada quedó sobre la superficie del mar. Durante un mes todo estuvo triste y en silencio. Luego, las aguas comenzaron a bajar hasta que apareció de nuevo la tierra. Entonces Chubé llegó hasta donde estaba Júli y le dijo:

- La tierra ya debe habese endurecido. Es tiempo de que usted vuelva a vivir en ella.

Y agregó:

- Pero antes les cambiaré a ustedes los dientes, y en lugar de dientes de piedra se los pondré de granos de maíz.

Y luego le dijo Chubé:

- Cuando sepamos que ya la tierra está dura, usted volverá y allí vivirá bien con los suyos.

Entonces enviaron al zopilote para que averiguara si la tierra ya se había endurecido.

El zopilote partió y sólo vio gente muerta que yacía sobre la tierra. Al posarse en el suelo sus patas se hundieron. Entonces alzó el vuelo y evitando poner sus patas en lá tierra todavía blanda, comenzó a devorar los restos de la gente metiendo la cabeza en los cadáveres. Por esta razón, y como resultado de su contacto con la sangre de aquellos cuerpos, el zopilote tiene la cabeza y las patas rojas.

Después, el zopilote regresó donde Chubé. Al llegar, éste le preguntó:

- ¿Cómo está la tierra?

El zopilote respondió:

- La tierra todavía está blanda.

Chubé le hizo entonces otra pregunta:

- ¿Por qué tiene usted sú cabeza y sus patas rojas?

El zopilote respondió:

- No lo sé.

Entonces Chubé envió al sapo, pero el sapo sólo llegó hasta la orilla del mar, y, sin poder avanzar, se regresó por el mismo camino sin llevar noticia alguna.

Esta vez Chubé envió a la paloma. Esta voló y se posó en la tierra todavía blanda. Entonces llegaron a ese lugar palomas de todas clases, pequeñas y grandes, y a todas se les hundieron las patas en la tierra que estaba teñida con la sangre de los muertos. Desde entonces, las patas de las palomas quedaron rojas para siempre.

Después, la paloma regresó donde Chubé, pero éste le dijo:

- Usted regresará y lo estará haciendo hasta que descubra algún rastrojo de vetetal. Entonces cogerá una hoja y me la traerá para que yo la vea.

Cuatro veces viajó la paloma, y en el cuarto viaje llegó con una hoja. Entonces Chubé le dijo a Júli:

- La tierra ha vuelto a ser habitable. Ya puede ir usted a vivir en ella.

Así fue como Chubé hizo que Júli volviera a vivir en esta tierra. Lo hizo después de la inundación que acabó con mucha gente, y tras la cual fueron contados los hombres que quedaron en el mundo.

Y luego así le habló Chubé a Júli:

- Ustedes han de amarse sin que jamás yo vuelva a tener noticias de que hacen cosas 
malas. Fue por eso que yo hice que aquella gente desapareciera, y bien puedo volver otra vez a hacerlo. Ustedes han de amarse y vivir contentos, como la gente recta en todos los lugares de la tierra. Yo, que todo lo sé, sabré cómo se están comportando.

Y agregó:

- Vuelva usted y viva bien en la tierra con su familia, porque usted estará en mi poder, en mi fuerza y en mi aliento.

Desde entonces, y como descendientes de los pocos que sobrevivieron a esa inundación, estamos nosotros en este mundo.

Se acabó.

\section{2 (1) Chuí chará dredabáble niiąin}

(2) N̈iáñ chui jải kléble ñañin. jải digé. (3) Kữä kléble tuí inạin jăi digé (4) mịii kléble tui núin. (5) Gíti gibí degâble kuéri guéri no îleáriga kuéri guéri. (6) Degéble kuări julita ge, (7) bá no mọin dagiadále, (8) bá nô yé buadále gadétrani. (9) Minyebále môni glé kirabále, (10) mônï ñąmbége, (11) môni bué miantåñấle. (12) Káre bá no môñ. buá chuí be drédaba. (13) Chará be jóge, (14) tiana be jói ré. (15) Bá nô mổ dagiadále. (16) Giráwa kuáü. mị̂̃. iále joyáble ché ñleáñga béga ta liñ. ge (17) Gíti degéble îleảnga kuéri guéri degéble gibi chugúbu nạmåñndige. (18) Âmâñ kóde bá no gére gáda, (19) gére begá mónigiti juiá gabadré gabadré, degéble kuáñ. ge. (20) Kuá no begáble wále, (21) kuá no begáble wẩle. (22) Kuá no begáble ta lini ge ạmąlinin mônin iá no gére begáble. (23) Giti kuáni suáli minin. iále joyáble gére bége, (24) anmâñ. kóde akáre unijogéble julita bli kóde. (25) Gíti kibí ché begáble nạmạndige. (26) Degéble ne suáli chuí chará be drédaba. (27) Jái badágli kuáni chá begánina ta lini ge anmalinin. (28) Ché tileániga yé gudá dále tuleátiga món̆ digé guá. (29) Gíti chuí chará dredabáble, (30) tuậ̉ joyáble ré ché wágaba segé. (31) Ché suáli unñjogéble bli kóde káre. (32)

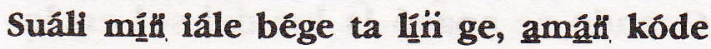
jęmlémble julita. (33) Begăñöna ta lï̈ ge amaliñi chebegéble. (34) Gíbi táu chuí chará chigebléni kogobëne. (35) Anạmạna digé ché jemlémble királe. (36) ïleånga kuéri guéri ạmalîn ché begéble inåin jegabále dabá. (37) Bái ché klé jăre. (38) Jải batágli.

(1) sol luz apagarse-rem comienzo (2) comienzo sol este estar-rem mundo este en (3) gente estar-rem vivir mundo este en (4) no estar-rem vivir bien (5) entonces advertencia poner-rem grande grande cacique grande grande (6) decir-rem gente toda dat (7) ustedes ag rec querer-imp-obl (8) ustedes ag cosa(s) hacer-imp-obl juntos (9) por+qué rec estar pelear-imp (10) rec matar (11) rec hacer de+todas+clases (12) así ustedes ag refl hacer sol fut apagarse (13) luz fut ir (14) mundo fut ir oscuro (15) ustedes ag rec querer-imp-obl (16) pero gente no nothaber llegar-rem nosotros cacique poner+atención querer para dat (17) entonces decir-rem cacique grande grande decir-rem plazo venir-imp cerca (18) eso por ustedes ag cerco levantar (19) cerco levantar alrededor casa-pos cada+una cada+una decirrem gente dat (20) gente ag poner-rem nada (21) gente ag poner-rem nada (22) gente ag poner+atención querer para dat nada+más refl int ag cerco poner-rem (23) entonces gente mitad no nothaber llegar-rem cerco poner (24) eso por aquellos morir-rem todos hambre por (25) entonces plazo nosotros poner-rem cerca (26) decir-rem ag mañana sol luz fut apagarse (27) esta última gente yo cumplir querer para dat nada+más (28) nosotros cacique cosa(s) comer para cacique refl en en+la+casa (29) entonces sol luz apagarse- rem (30) mundo llegar oscuro nosotros ojo(s) en (31) nosotros mitad morirrem hambre por así (32) mitad no nothaber ponertatención querer para dat eso por perderse-rem todos (33) cumplir querer para dat nada+más quedar-rem (34) plazo diez+días sol luz venir-rem-de+nuevo otra+vez (35) eso en nosotros desaparecer-rem muchos (36) cacique grande grande nada+más nosotros poner-rem lugar en+todas+partes-adv tierra (37) porteso nosotros estar aquí (38) esto último 
Cuando se apagó la luz del sol en los primeros tiempos

En los comienzos del mundo ya estaba el sol. También en el mundo había gente, pero esa gente no era buena. Por eso nuestro gran cacique les hizo una advertencia para que mejoraran su proceder. El le dijo a la gente:

- Ustedes deben amarse y hacer buenas obras en conjunto. ¿Por qué ustedes están siempre peleando, matándose y haciendo toda clase de desmanes?

Y agregó nuestro gran cacique:

- Si ustedes continúan así harán que se apague la luz del sol y que todo el mundo quede a oscuras.

Sin embargo, la gente no le prestó atención.

Al tiempo, y al ver que así procedían, nuestro gran cacique les dijo:

- Ya está muy cerca el plazo que yo puse para que la luz del sol se apague. Por eso cada uno de ustedes debe levantar un cerco alrededor de su casa.

$\mathrm{Al}$ escuchar esto, sólo algunos le prestaron atención y no tardaron en levantar los cercos, pero los más no le hicieron caso y nada hicieron. Fueron estos últimos los que murieron.

Después dijo nuestro gran cacique:

- El plazo se ha cumplido. Mañana se apagará la luz del sol.

Y agregó:

- Sólo estarán protegidos los que han puesto atención a lo que yo he dicho.

Entonces se apagó la luz del sol y el mundo quedó completamente a oscuras. Mucha gente murió de hambre, ya que sólo había comida en la casa del gran cacique. Todos aquellos que no hicieron el cerco alrededor de la casa, desaparecieron; únicamente quedaron los que le habían prestado atención al gran cacique.

A los diez días la luz del sol reapareció. Eran muchos los que para entonces habían muerto.

Después, nuestro gran cacique envió a la gente a vivir en distintas partes de la tierra. $Y$ aún seguimos en ellas.

Se acabó.

\section{3. (1) Koróyi Tóndo Mési Tóndo}

(2) Nịạin kuáï kléble tui kuáï kuéri tảia. (3) Kuéri guéri ka juáni klêble Mési Tôndo Koróyi Tóndo dabáia, (4) kléble tui ñạẩ jăi digé. (5) Giráwa Mési Tóndo táia nansêre, Koróyi Tóndo táia nú. (6) Kuáñ. chigéble

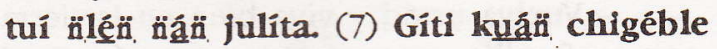
kiru bué nañére, (8) mônï. báde, (9) mônin. Hạmbége, (10) mót bué miantäîẩle. (11) Gíti degéble Koróyi Tóndo, minyebále kuáü glé kirabáde királe, (12) mổ̆ dagiadále mịhi bá ge. (13) Amá lị̂ gíti klé mổỉ bué nạnsére királe. (14) Mési Tôndo degêble klébi núü chá liini, (15) kiru nụin degéble no. (16) Giti Mési Tóndo ta joyáble dibi jâi gagáin glé, degéble debáia Koróyi Tondo ge. (17) Koróyi Tóndo degéble miạle ${ }^{12}$, dibi gagandále ché jẹmlendále julíta, degéble no. (18) Ché jẹmlẹndále tialléme chá ge, degéble Mési Tóndo. (19) Giráwa Mési Tóndo mōin iá nọ gibí degáble. (20) Julị mốb̈ iá no wiámble. (21) Degéble julị no gabái mổỉ táia segé, (22) degéble chá be Koróyi Tóndo nubbayáde kíru kuéri be chigéga kuá lị̂i. (23) Chá be nưbayáde, degéble no. (24) Nuiiä jáimble chu éde chuí bu. (25) Julinï chigéble gli gligada digé dabá mônio muiánde. (26) Kléble mónin muiánde chu éde chuí bu chuí mải. (27) Degêble juli no minyebále Koróyi Tóndo mịin iảle kuạin káge kỉu jinạande chá ge, degéble no. (28) Koróyi Tóndo degéble no klé yé mâñ. suáde ché ge. (29) Ché glé alliẹndaba kiru kuéri káre. (30) Jogá kíru jinạande ke degêble kuáin guá ge no. (31) Joyáble julịī namạndige. (32) Julinin degéble kiru kuéri mua liñ. (33) Bá be kanẹentinama dibí jái kóde, (34) jẹmlé unïjóge be bli kóde, degéble julị no. (35) Kuáä degéble chédre yé mạni buadále ba no degé. (36) Juli no degéble kuáti jải ge, (37) bá no degé Korôyi Tôndo dibí kuéri be chigéga. (38) Môñ ṫleáñgada móñ. nạmạndige no dibí kuéri be chigéga, (39) gíti Koróyi Tóndo jogadále Mési Tôndo nạmándige kú nắnde. (40) Mịin kú kéda ke. 
(41) Jogá nạnde kuáde kuou kuamại kuabága dále. (42) Jogadále wịne. (43) Dibí jái be kuát kąné̉̆hama julita, (44) giráwa Koróyi Tôndo jogadále wíne badágli. (45) Mési Tóndo be chigé móĭ gígeke, (46) kú kegadále siróge no. (47) Chigedále góglą̆, (48) kú siróge juandále, wiăna badadảle chugá segé. (49) Anamănan digé be uninjóge. (50) Gíti Mési Tôndo jải dibiả badá chugá dobógla. (51) Amanin. giri dibi be chigéni tuigáni kogobéne, (52) giráwa kuáni be jemlé bli kuéri góde dibí jái kóde. (53) Dibi kuéri minin buále jăi chá glé suáde mónin ${ }^{13}$ ge, degéble julí no. (54) Anạmáli digé juli no degéble, dibi kuéri wiále núbi chá ge, (55) mliểi kuérỉ wiále núü chá ge, (56) yé julíta kuéri be chigéga móni ge wiâle julita chá ge. (57) Kưru yé mảini kiru chá no suadále môin ge, (58) môñi. béga tádre, degéble no. (59) Anamaải digé Koróyi Tôndo kíru wiảmble, (60) Amạñ kóde joyáble tádre, (61) káre buáble no. (62) Dibi kuéri chigebléga. (63) Gidi Koróyi Tóndo jăi namạndige bli kléble kuáñ. ge, (64) kléble bli ñlié uñ̄. mlâanga miăle dibí jåi no. (65) Kuánin bitigá jogéble bli góde badágli. (66) Giti Mési Tơndo chigéble Koróyi Tôndo namạndige. (67) Chigéble ñảin gudêre dabá dáñgle,

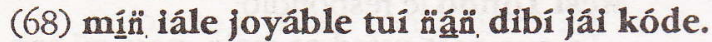
(69) Gudére dabá dáñgle kanąũ. gadá bága. (70) Degéble chá no miále chá

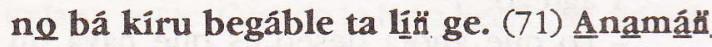
digé dibí kuéri be chá tiambége káre. (72) Chá chugú monoin. gíge bá ge, (73) bá no chá gáda bá nigáru káre. (74) Gíti kuáñ no kú degabléga siróge no. (75) Degabléga no wiâña badáble chugá segé no. (76) Anamanañ. digé jogéble dabá, uñojogéble. (77) Giti dibiá badáble chugá dobógla.(78) Giti dibi chigéble tuiga. (79) Anamáñ digé kuáñ jẹmlếmble kuéri ñâñ jegabále dabá. (80) Koróyi Tôndo âmallini nåmándige bli kléble. (81) Âmåñ. kóde ché glé ñạñ̄. monạande. (82) Jái batágli.
(1) Koróyi Tóndo Mési Tóndo (2) comienzo gente estar-rem vivir gente grande pensamientopos (3) grande grande nombre coger estar-rem Mési Tóndo Koróyi Tóndo hermano(s)-pos (4) estar-rem vivir mundo este en (5) pero Mési Tôndo pensamiento-pos malo Koróyi Tóndo pensamiento-pos bueno (6) gente venir-rem vivir mucha lugar(es) todos (7) entonces gente venir-rem hecho(s) hacer malos (8) rec golpear (9) rec matar (10) rec hacer de+todas+clases (11) entonces decir-rem Koróyi Tondo por+qué gente estar pelear mucho-adv (12) rec amar-imp-obl no ustedes dat (13) eso para entonces estar rec hacer mal mucho-adv (14) Mési Tóndo decir-rem estarya bueno yo para (15) noticia buena decir-rem ag (16) entonces Mési Tóndo querer llegarrem temblor este ocurrir estar decir-rem hermano-pos Koróyi Tóndo dat (17) Koroyi Tóndo decir-rem no-nothaber temblor ocurrir-imp-obl nosotros perder-imp-cond todos decir-rem ag (18) nosotros perder-impobl no+importar yo dat decir-rem Mési Tôndo (19) pero Mési Tóndo refl int ag plazo ponerrem (20) mono+congo refl int ag saber-rem (21) decir-rem mono+congo ag solo refl pensamiento-pos en (22) decir-rem yo fut Koróyi Tóndo avisar cataclismo grande fut venir-dir gente para (23) yo fut avisar decirrem ag (24) lluvia caer-rem sol uno sol dos (25) mono+congo venir-rem árbol tronco en tierra refl llorar (26) estar-rem refl llorar sol uno sol dos sol tres (27) decir-rem mono+congo ag por+qué Koróyi Tóndo no nothaber gente enviar noticia buscar yo dat decir-rem ag (28) Koróyi Tóndo decir-rem ag estar cosa qué avisar nosotros dat (29) nosotros estar tranquilo(s) noticia grande así (30) vaya noticia buscar dat decir-rem hombre de+latcasa dat ag (31) llegar-rem mono+congo donde (32) mono+congo decirrem noticia grande ustedes para (33) ustedes fut terminar temblor este por (34) perder morir fut hambre por decir-rem mono+congo ag (35) hombre decir-rem nosotros-pl cosa qué hacerimp-obl usted ag decir (36) mono+congo decir-rem hombre este dat (37) usted ag decir 
Koróyi Tốndo temblor grande fut venir-dir (38) rec juntar ustedes donde ag temblor grande venir-dir (39) entonces Koróyi Tóndo ir-imp-obl Mési Tóndo donde cacao pedir (40) no cacao dar dat (41) vaya pedir una+vez dos+veces tres+veces cuatro+veces para (42) ir-imp-obl tranquilo (43) temblor este fut gente terminar toda (44) pero Koróyi Tóndo ir-impobl tranquilo último (45) Mési Tóndo fut venir refl humillarse (46) cacao poner-imp-obl cuello ag (47) venir-imp-obl hacia+la+casa (48) cacao cuello coger-imp-obl agitar+moviendo+hacia+ arriba+y+hacia + abajo+dentro+del + puño poner-imp-obl cabeza en (49) eso en fut morir (50) entonces Mési Tóndo esta enterrar tierra cabeza hacia+abajo (51) eso después temblor fut venir-de+nuevo parar-de+nuevo otra+vez (52) pero gente fut perder hambre grande por temblor este por (53) temblor grande no hacer-imp esto yo estar avisar ustedes dat decir-rem monotcongo ag (54) eso en mono+congo ag decir-rem temblor grande saber-imp bien yo dat (55) viento grande saber-imp bien yo dat (56) cosa(s) todas grande(s) fut venir-dir ustedes dat saber-imp todas yo dat (57) noticia(s) cosa(s) qué calamidad(es) yo ag avisar-imp-obl ustedes dat (58) refl poner preparar-irr decir-rem ag (59) eso en Koróyi Tóndo noticia saber-rem (60) eso por llegar-rem prepararse-irr (61) así hacer-rem ag (62) temblor grande venir-remdir (63) entonces Koróyi Tóndo este donde comida estar-rem gente dat (64) estar-rem comida cocinar olla botar-dir no-nothaber temblor este ag (65) gente pueblo ir-rem comida por última (66) entonces Mési Tóndo venirrem Koróyi Tóndo donde (67) venir-rem lugar gatear tierra trastabillar-irr (68) no nothaber llegar-rem estar+de+pie lugar temblor este por (69) gatear tierra trastabillar-irr brazo(s) pierna(s) cuatro (70) decir-rem yo ag no-nothaber yo ag usted advertencia poner+atención-rem querer para dat (71) eso en temblor grande fut yo matar también (72) yo venir-irr refl humillar usted dat (73) usted ag yo coger usted lado también (74) entonces hombre ag cacao arrancar-rem-dir cuello gen (75) arrancar-rem-dir ag agitar+moviendo+ hacia + a rriba $+y+a b a j o+d e n t r o+d e l+p u n ̃ o$ poner-rem cabeza en ag (76) eso en ir-rem tierra morir-rem (77) entonces enterrar ponerrem cabeza hacia+abajo (78) entonces temblor venir-rem parar (79) eso en gente perderserem grande lugar en+todas+partes-adv tierra (80) Koróyi Tóndo sólo donde comida estarrem (81) eso por nosotros estar mundo uno+a+uno (82) esto último

\section{Koróyi Tôndo y Mési Tóndo}

En los comienzos del mundo había en la tierra personas importantes y muy poderosas. Entre ellas se contaban dos hermanos llamados Mési Tóndo y Koróyi Tóndo.

Sin embargo, ambos eran diferentes, pues en tanto que Mési Tóndo era una mujer de mala índole, su hermano Koróyi Tóndo era un hombre de buenos sentimientos.

En aquel tiempo ya el mundo se había poblado de mucha gente, pero aquella gente hacía cosas malas: se golpeaban, se mataban y cometían toda clase de desmanes.

Cierta vez, Koróyi Tóndo le dijo a su hermana:

- ¿Por qué todos, incluso usted, se pelean tanto? Lo que están haciendo es muy malo.

Mési Tóndo le respondió:

- Lo que para usted es malo, para mí son cosas buenas.

Y agregó:

- Lo que ahora deseo es que haya un gran temblor.

Koróyi Tóndo le replicó:

- No, eso no debe ocurrir porque todos desapareceríamos.

Mési Tôndo dijo entonces:

- A mí no me importa que todos desaparezcamos.

No obstante, sucedió que al expresar este deseo, Mési Tóndo había desencadenado las fuerzas que se abatirían sobre la tierra como un gran temblor.

El único que supo este hecho, muy lejos de allí, fue el mono congo. Y el mono congo pensó entonces: "Tengo que avisarle a Koróyi Tóndo el 
gran cataclismo que se avecina para toda la gente". Y continuó diciéndose: "Yo debo avisarle".

Llovió copiosamente durante dos días. Entonces el mono congo se arrimó al tronco de un árbol y allí comenzó a llorar. Estuvo llorando uno, dos, tres días. Llorando decía:

- ¿Por qué Koróyi Tóndo no envía a alguien para que yo le haga saber lo que va a ocurrir?

En tanto, Koróyi Tóndo dijo:

- Alguien que está muy lejos quiere comunicarnos algo. Es una noticia muy importante y nosotros estamos aquí muy tranquilos.

Entonces le dijo a uno de los hombres de la casa:

- Vaya usted y camine hasta encontrar a quien tiene que darnos esa noticia tan importante.

El hombre partió y caminó hasta llegar donde estaba el mono congo. Al verlo, éste le dijo:

- Tengo una noticia muy importante para ustedes. Todos desaparecerán por causa de un gran temblor que se avecina.

Y agregó:

- En ese temblor se perderán los alimentos y será mucha la gente que va a morir de hambre.

El hombre le preguntó:

- ¿Qué podemos hacer para salvarnos?

Entonces el mono congo habló así:

- Regrese usted y dígale a Koroyi Tóndo que habrá un gran temblor. El debe reunir a toda su gente. Cuando lo haya hecho, se dirigirá hasta la casa de Mési Tóndo y le pedirá cacao. Ella no se lo dará. El deberá regresar a pedírselo una, dos, tres, cuatro veces. Después de la cuarta negativa, volverá a su casa y allí se quedará traquilo. Entonces comenzará el temblor que acabará con toda la gente, pero a Koróyi Tóndo y a los suyos nada habrá de ocurrirles porque en su casa todo permanecerá quieto. Luego, durante el temblor, Mési Tóndo llegará arrepentida y buscando ayuda. Como muestra de su humillación, ella llevará una sarta de semillas de cacao atada al cuello. Koróyi Tóndo deberá arrancársela y cogiéndola en su puño, la agitará hacia arriba y hacia abajo junto a la cabeza de ella. Al hacer esto, Mési Tóndo morirá. Luego, él deberá enterrarla con la cabeza hacia abajo. Cuando haya hecho esto, el temblor cesará de inmediato.

Y agregó:

- En este temblor morirá mucha gente pues durante el cataclismo se perderá toda la comida. Yo se los aviso para que ustedes estén preparados y nada les ocurra.

Y terminó diciendo el mono congo:

- Yo sé que ocurrirá este temblor, y sé de los huracanes, así como sé de todos los cataclismos que sobrevendrán. Yo todo lo sé, y por eso, y para que estén preparados, les estoy dando este aviso.

Así le habló el mono congo al hombre, y por eso Koróyi Tốndo supo lo que se avecinaba y se preparó para ello haciendo lo que el mono congo había dicho.

Entonces comenzó a temblar muy fuerte. En todas las casas el temblor hacía caer las ollas con comida, destruyendo también las cosechas. Sólo donde Koróyi Tóndo había alimentos. Alli el temblor no botó la olla donde se estaba preparando la comida. Todos los demás se quedaron sin sustento.

Mientras temblaba cada vez más fuerte, Mési Tóndo llegó a la casa de Koróyi Tóndo. Venía trastabillando y cuando se caía se arrastraba sin lograr ponerse de pie por la fuerza del temblor. Así llegó hasta donde su hermano, y mientras gateaba aferrándose al suelo con pies y manos, le dijo a Koróyí Tôndo.

- Yo no le puse atención a su advertencia, y por eso en este temblor también voy a morir.

Y suplicando, agregó:

- Por favor, jacójame en su casa!

Entonces el hombre que estaba junto a Koróyi Tóndo le arrancó la sarta de semillas de cacao que Mésí Tóndo llevaba en el cuello, y, cogiéndolas en su puño, las agitó con movimientos hacia arriba y hacia abajo, haciéndolas sonar junto a la cabeza de la mujer. Al instante ella se desplomó muerta. Luego Koróyi Tôndo la enterró con la cabeza hacia abajo, y, en ese momento, el temblor cesó. 
En ese temblor desapareció mucha gente en todo el mundo. Muchos murieron de hambre, pues toda la comida se perdió. Después de aquello fueron contados los que quedaron sobre la tierra.

Se acabó.

\section{4. (1) Bogá Dadiá Nuí Dadiá}

(2) Nui Dadiá Bogá Dadiá lảna kuiôm kléble

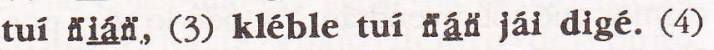

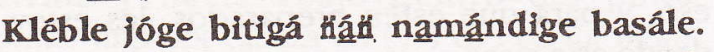
(5) Klẻble mị̂̉ wăle chúkka ạmạn̆ góde, (6) kléble mini̊ wålle kuáï julita ge. (7) Giráwa cheemáña kuióm tá digé kuéri giráwa wịne. (8) Kléble chigé wịe ñăni julita, (9) giráwa kuáñ. ge kléble miñ̄. wâlle. (10) Giráwa wine kuáñi. julita dagéble no ge. (11) Kléble jóge basále kediále kléble kë kéde ke, (12) gli badá kéde ke, (13) yé wậle kéde ke. (14) Giráwa mịỉ iále jogóyi dáge digé. (15) Degêble no minnyebále nạñwále kuáäi giti mịin iále begedále niéru. (16) Amạnin kóde chugaméni dadále jogadále bási nạnsére (17) Âmáï kóde ále táia juéêi chí, degéble no (18) Ále i guára gúge degêble kuăha julita wiêthgiti no ke. (19) Kuán̆ joyáble jolérikabe gidáde. (20) Gibi degáble chuí bága no. (21) Suále kuáü chigéble begadále. (22) Jolêênkabe júli jingámble éde no, (23) kímo jinámble éde no káre. (24) Begáble no kú jăi móin segé táñigle krusóle. (25) Gíti inạini jegeblétaba julita, (26) nuíñ chigéble inận gadáde. (27) Chigéble kuéri nuịị jảimble bitáte dabá, (28) gídi tigebléga. (29) Degêble kuá no wạle klé kuán̈ muire óde monekéó glânin. (30) Chá mịin iále begá ta lịin ge degéble no káre muíre muire degéble káre. (31) Gíti jogeblénị. (32) Báge gadáde ạmạin gire chudé julita chigéble bli chigéble tugéga ñâni julíta. (33) Giti blí guá ạmallịin chebegéble ñåñ̄. jegebále dabá. (34) Cheemáña kuióm nạmándige bli kléble, (35) bli ba miantañwále kléble núñ julíta. (36) Nạañ bitigá gití tugebléga julíta. (37)
Báge godóu kưát chigéble untijóge bli kóde. (38) Kuán kléble chigé basăle ke mỉỉ iảle yé kéde ke. (39) Kuâă suáli untijogéble julita.

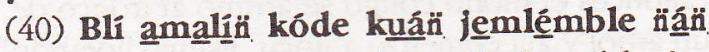
chigéble (41) Kuedige kuáni chebegéble éte éte ůăin jegabále dabá, (42) girảwa gadále julita blí góde. (43) Degéble no, kuáñ chigébi unñjóge julita, (44) ále bli kedéni ke, degéble no. (45) Ché glé tảia juẹể chí mua lịin, (46) ñạmệ̉i mịin iále jogadále wậle. (47) Gíti ạmåñ dále, degéble no, chudé kéde ke. (48) kedáble kuáni ge, (49) kuá no chudé sigåble toaniñ. jegabále. (50) Chudé ạmạiti klé dabá, (51) ché glé dabá kâre. (52) Jái batágli.

(1) Bogá Dadiá Nuí Dadiá (2) Nui Dadiá Bogá Dadiá hermano(s) dos estar-rem vivir comienzo (3) estar-rem vivir tierra esta en (4) estar-rem ir pueblo lugar donde caminar-imp (5) estar-rem ver sin+valor pequeño(s) $+y+f e o(s)$ eso por (6) estar-rem ver sin+valor gente toda dat (7) pero él dos poder en grande pero callado(s) (8) estar-rem venir callado(s) lugar todos (9) pero gente dat estar-rem ver sin+valor (10) pero callado(s) gente toda enojar-rem ag dat (11) estar-rem ir caminarimp adrede estar-rem piedra(s) dar dat (12) árbol palo dar dat (13) cosa(s) sin+valor dar dat (14) pero no no+haber llegar+a+enojar en (15) decir-rem ag por+qué seso gente en no no+haber ver-imp-obl hacia+adelante (16) eso por permitir-otra+vez si-adv ir-imp-obl más malo(s) (17) eso por vamos poder-pos coger un+poquito decir-rem ag (18) vamos maíz mazorca pudrir decir-rem gente toda delante ag dat (19) gente llegar-rem nada+más reir (20) plazo poner-rem sol cuatro ag (21) avisar-imp gente venir-rem mirar-imp-obl (22) nada+más huérfano buscar-rem uno ag (23) primogénito buscar-rem uno ag también (24) poner-rem ag cacao beber refl dentro cruzar-irr cruz-adj (25) entonces lugar oscurecerse-rem todo (26) lluvia venir-rem lugar sonar (27) venir-rem grande lluvia caer-rem un+rato tierra (28) entonces escampar-rem-dir (29) decir-rem gente ag sin+valor estar gente mujer engañar 
ellos para (30) yo no nothaber ponertatención querer para dat decir-rem ag también mujer mujer decir-rem también (31) entonces ir-rem-otra+vez (32) semana una eso después semilla(s) todas venir-rem alimento venir-rem pudrir-dir lugar todos (33) entonces alimento en+la+casa solamente quedar-rem lugar en+todas+partes-adv tierra (34) él dos donde alimento estar-rem (35) alimento forma $\mathrm{de}+$ todas + clases estar-rem bueno todo (36) lugar pueblo en pudrir-rem-dir todo (37) semana dos gente venir-rem morir hambre por (38) gente estar-rem venir caminar-imp dat no no+haber cosa dar dat (39) gente mitad morirrem toda (40) hambre sólo por gente desaparecer-rem mundo venir-rem (41) mucho+tiempo gente quedar-rem uno uno lugar en+ todas+partes-adv tierra (42) pero flaco(s)-adj todos hambre por (43) decir-rem ag gente venir-ya morir toda (44) vamos alimento darotra+vez decir-rem ag (45) nosotros estar poder-pos coger un+poquito nosotros para (46) para+que no nothaber ir-imp-obl nada (47) entonces eso para decir-rem ag semilla(s) dar dat (48) dar-rem gente dat (49) gente ag semilla(s) sembrar-rem lugar en+todas+partesadv (50) semilla(s) esas estar tierra (51) nosotros estar tierra también (52) esto último.

\section{Bogá Dadiá y Nuí Dadiá}

Nui Dadiá y Bogá Dadiá eran dos hermanos que vivían en los primeros tiempos de este mundo. Ellos a menudo salían a caminar por el pueblo cuya gente los despreciaba ya que los dos hermanos eran pequeñitos y feos. Sin embargo, aunque ambos tenían grandes poderes, nada decían, y muy callados iban y venían por todas partes.

Como ellos no respondían a las muestras de desprecio, esto provocaba el enojo de los habitantes del lugar. Por eso solía ocurrir que cuando ellos salían a caminar, la gente les diera piedras o palos diciéndoles en tono de burla que se los comieran, o bien les ofrecían regalos para luego darles cosas sin valor. Con todo, ellos nada decían y jamás mostraban enojo.
Sin embargo, cierto día ambos dijeron:

- ¿Por qué la gente es incapaz de ver lo que puede pasar si continúan procediendo así con nosotros? Si permitimos que nos sigan haciendo todo esto, ellos serán cada día peores.

Y agregaron:

- Para terminar con esto usaremos un poquito de nuestro poder.

Entonces fueron donde estaba la gente del pueblo y, ante todos, dijeron:

- Vamos a hacer que el maíz y todos los alimentos se pudran.

$\mathrm{Al}$ escuchar esto, todos se echaron a reir.

Tras esto, ellos le dijeron a la gente que harían lo anunciado dentro de cuatro días, y que para esa fecha todos podrían venir a ese lugar para verlo.

Entonces los dos hermanos buscaron a un huérfano y a un primogénito. Al llegar el cuarto día, y ante toda la gente, hicieron que el huérfano y el primogénito pusieran en el lugar cuatro cruces colocadas respectivamente hacia el este, el oeste, el norte y el sur, y luego que ambos bebieran cacao en el centro del espacio limitado por las cruces ${ }^{14}$.

Cuando el huérfano y el primogénito terminaron de beber el cacao, todo el lugar se oscureció y retumbando con gran estruendo cayó un fuerte aguacero que sólo duró unos momentos, pues pronto escampó y todo el lugar se aclaró.

De inmediato, los hombres que estaban allí dijeron:

- Lo que han hecho no es nada. A lo más con esto quizás podrán engañar a algunas mujeres.

Y entonces dijeron las mujeres:

- A nosotras tampoco nos han engañado.

Después de esto, todos se fueron.

Una semana después, en todos los lugares de la tierra se pudrieron todas las semillas y todas las cosechas. De improviso, la gente se quedó sólo con el alimento que en ese momento cocinaba. Sin embargo, en la casa de ambos hermanos, había alimentos en gran cantidad y la más grande variedad de hermosos granos. En el resto de las casas, todo el alimento se había podrido. 
Durante la segunda semana que siguió a esto, la gente empezó a morir de hambre. Muchos caminaban de casa en casa pidiendo comida, pero nadie tenía algo que darles.

Al poco tiempo, la mitad de la gente ya había muerto, en tanto que día a día el hambre hacía desaparecer a más gente de la tierra.

Al fin, en el mundo ya no quedaban sino contados habitantes, y todos ellos flacos y debilitados por el hambre.

Entonces Bogá Dadiá y Nui Dadiá dijeron:

- Pronto desaparecerá toda la gente; vamos a darles otra vez comida.

$\mathrm{Y}$ agregaron:

- Usaremos de nuevo un poquito de nuestro poder para que puedan comer y tengan en adelante mucho cuidado en no volver a cometer disparates.

Después de hablar así, ambos hermanos repartieron semillas entre la gente. Y la gente sembró las semillas en todas partes. Son éstas las semillas que hasta hoy existen en la tierra en la que también nosotros vivimos.

Se acabó.

\section{Comentarios}

De manera introductoria a estos comentarios debemos hacer dos alcances que estimamos pertinentes. El primero se refiere al hecho de que al margen de estos cuatro textos, existen en el corpus de relatos bocotás que hemos recogido, dos pasajes cuyos contenidos guardan relación con cataclismos. Ambos se encuentran en el relato Chibiá chui dige dái ('La madre del Sol y de la Luna') (Margery Peña, 1990), en el cual se yuxtaponen el tema del gran incendio, que en esta versión es provocado por la madre del Sol y de la Luna, y el de la gran inundación, originada en este contexto por la tormenta que desencadena el Rey del Trueno para apagar el fuego.

El segundo alcance se refiere a que en relación con los textos aquí presentados, nuestro informante nos señaló que, con exclusión del primero, los relatos segundo, tercero y cuarto - correspondientes respectivamente a la larga noche, el gran temblor y la gran hambrunaconstituyen para los bocotás una secuencia de tres calamidades que habrá en el futuro de completarse con una cuarta -de naturaleza ignoradacuando se produzca el fin del mundo.

Anotados ya ambos alcances, cabe iniciar estos comentarios aludiendo al hecho de que los cataclismos -y con ellos la consecuente destrucción del mundo- constituyen una temática siempre presente en la mitología de los pueblos indoamericanos. De paso conviene aquí señalar que entre las distintas formas que los cataclismos alcanzan en este ámbito, son tres las más reiteradas, a saber: "el diluvio (la inundación)", "el gran incendio" y "la larga noche". Otros cataclismos que en los materiales que obran en nuestro conocimiento presentan una menor frecuencia son: "la sequía", "la gran hambruna", "la peste", "la lluvia de piedras", "el aniquilamiento de la humanidad por fieras", "el gran temblor", "el gran viento", "la caída del cielo", común entre los pueblos del Gran Chaco, y "la gran helada", que aparece con frecuencia en las culturas del Cono Sur. A estos cataclismos pueden sumarse algunas otras manifestaciones al parecer de bajísima frecuencia, como lo son "la gran pestilencia", que según la mitología quechua terminó con la tercera edad en los tiempos de Huayna Capac (Waman Puma de Ayala, Nueva Corónica y Buen Gobierno. 1567-1613, en Lara, 1976: 47; Rowe, 1946: 319), "la muerte por el horror colectivo" que en la mitología pipil provocó la primera aparición del sol (Schultze Jena, 1935/1977: 78-79), y -aunque no se trate propiamente de un cataclismo, pero de consecuencias análogas- "el gran genocidio", presente en la mitología de los bororo (Colbacchini y Albisetti, en Wilbert y Simoneau, 1983: 73-75).

En lo que corresponde al material aquí expuesto, cabe anotar que por sus contenidos los cuatro textos se ubican en el marco de los que el Motif-Index de Stith Thompson clasifica como "motivos mitológicos", correspondiéndoles por su temática la indexación A1000. "Calamidades y renovaciones del mundo" is A su vez, y en la perspectiva que establece la 
citada obra, otros motivos contenidos en los cuatro relatos bocotás corresponden a los catalogados como A1003. "La calamidad como castigo por faltas", implicando Q411. "La muerte como castigo"; A1005. "Prevención de la vida durante una calamidad mundial", y, en lo que respecta a las figuras protagónicas, el motivo Q150. "La inmunidad en el desastre como recompensa".

No obstante, determinados estos elementos comunes, interesa plantear estos comentarios en los elementos específicos que aportan los textos presentados.

\section{1. "El cataclismo que Chubé le anunció a Júli"}

Como ya lo señaláramos, este relato, que es el más extenso de los cuatro, constituye en la cultura bocotá un episodio contextualmente separado de la secuencia conformada por los tres restantes. En el contenido del texto, este hecho se ve corroborado por la participación en él de Chubé, el gran transformador y héroe cultural de los bocotás, figura que no interviene en los otros tres relatos.

La intervención de Chubé, así como su aviso a Júli de la inminencia del cataclismo elementos que involucran los motivos A182.3. "Dios les habla a un mortal", y A1015. "Inundación causada por dioses u otros seres superiores -constituyen elementos que operan, al parecer, en función del desarrollo del relato de acuerdo con el mito judeo-cristiano del Arca de Noé. Como motivos comunes entre este último mito y el relato bocotá pueden citarse los indexados como A1021. "Diluvio: escape en un barco (arca)"; A1021.1. "Parejas de animales en el arca"; A1021.2. "Pájaros exploradores enviados fuera del arca", y A2291. "Características de animales adquiridas durante el diluvio".

Debemos señalar en este punto que la mayor parte de los relatos indoamericanos referentes al diluvio (o inundación) no se corresponden con este esquema, impuesto en las culturas aborígenes por la influencia del cristianismo. Así, en lo que respecta al medio de salvación de las aguas, los elementos predominantes en la mitología indoamericana son el refugio en un árbol (A1023) o en un cerro (A1022), que ocasionalmente crece a medida que suben las aguas, y, en no contados casos, el refugio en una cueva o en un agujero cubierto con determinados materiales (A1024.).

Por otra parte, sin entrar a considerar relatos que constituyen meras adaptaciones del pasaje bíblico a lenguas vernáculas, como son los casos de una versión sateré-maué (Uggé, 1991: 194-195), cultura de estirpe tupí, y, en el ámbito de las lenguas caribes, de una narración makuxi que Amodio (1989:101-102) cita como ejemplo de la influencia del movimiento aleluya en la zona fronteriza de Brasil, Venezuela y Guyana, debe señalarse que en los textos que, como el bocotá, siguen el esquema del mito del Arca de Noé, es frecuente la ausencia o el reemplazo de determinados elementos existentes en el correlato bíblico.

Así, y a manera de ejemplos, en relación con la figura que provoca el diluvio, en una versión quechua (Juan de Velasco, Historia del Reino de Quito en la América Meridional, en Krickeberg, 1928/1985: 186) ésta es una gran serpiente que al ser herida por los hijos de Pacha, se venga inundando el mundo. A su vez, en un relato lacandón (Boremanse, 1989:70) quien origina el cataclismo es Hach Ak Yum, uno de los dioses creadores, quien le ordena a su yerno construir un barco; en tanto que en una narración kogui (Fischer y Preuss, 1991: 3940) es el Jefe Zántana quien abre las puertas del cielo para que lloviera cuatro años enteros, pero viendo lo que éste iba a hacer, uno de los Mamas, Seizankua, construye un barco donde se refugian su hijo y todos los animales.

En casos como el de este último relato, la variación del esquema básico del mito bíblico se cumple en la forma en que la deidad le comunica al superviviente el cataclismo que se avecina. En varias versiones mocoví (Terán, en Wilbert y Simoneau, 1988: 94 y ss.), Dios toma el aspecto de un perro sarnoso para avisarle la inminencia del diluvio y ordenarle construir un barco, al único hombre del pueblo que lo había acogido en su casa. 
Otro elemento del mito bíblico donde se presentan variaciones es el arca. En una versión jacalteca (Montejo, 1985: 417) se trata de una casa que se eleva sobre las aguas. De manera análoga, en la versión quecha recién citada, Pacha y sus tres hijos construyen una casa sobre la cima del Pichincha donde la familia se refugia en compañía de los animales.

Finalmente, un elemento del mito bíblico que no varía -con excepción entre los aquí citados de los relatos kogui y lacandón en los que no se da- es el de los pájaros que son enviados fuera del arca, función que cumplen el zopilote (o el cuervo) y la paloma.

En esta perspectiva, la versión bocotá del diluvio no elide ni reemplaza ninguno de los elementos que concurren en el esquema del mito bíblico. Sólo cabría hacer mención como un aporte novedoso en relación con el tratamiento del motivo A2291. "Características de los animales obtenidas durante el diluvio", del pasaje referente al origen del color rojo de la cabeza y de las patas del zopilote, así como del color también rojo de las patas de las palomas.

No obstante, se aprecia en esta versión bocotá la incorporación al mito de determinados elementos a los que a continuación pasaremos a referirnos.

El primero de estos elementos se refiere a la actancia protagónica, Júli, cuyo significado en bocotá es el de 'huérfano'. De hecho, lo cual puede ser verificado en el cuarto relato, la condición de "huérfano" o de "primogénito" implica para estos individuos constituirse en figuras de especial relieve en muchas de las ceremonias de este pueblo. En este sentido, la elección que Chubé hace de un huérfano para anunciarle el cataclismo y determinar su salvación, implica un enfoque autóctono de uno de los elementos del mito.

Una función análoga la desempeñan las alusiones a las fiestas y ceremonias bocotás peonadas, balserías, chichadas y la ceremonia de la claridad-que se encuentran en la primera parte del relato y que dotan al contenido de reiteradas referencias a elementos culturales de este pueblo.
Un tercer elemento lo conștituye la incorporación en el desarrollo del mito del motivo A1316.6. "Origen de los dientes". En este sentido, la primitiva posesión de dientes de piedra y su posterior reemplazo por dientes de maíz, conforma un episodio ausente en todas las versiones propiamente indoamericanas del mito de las que tenemos conocimiento, sin que por otra parte hayamos encontrado alusiones a este hecho en el corpus de la tradición oral bocotá que hasta la fecha hemos recogido.

Por último, un elemento también ajeno al desarrollo del mito y, en especial, al motivo A1021.2. "Pájaros exploradores enviados fuera del arca", lo constituye la inclusión del sapo entre los animales a los que Chubé envía a averiguar si la tierra está ya seca.

La explicación que encontramos más adecuada para la inclusión del sapo en el pasaje señalado se origina en un hecho propiamente narrativo al que por sus características podemos denominar "interpolación de correlatos".

En este caso concreto, conviene señalar que algunas narraciones obtenidas de nuestro informante incluyen episodios en los que varios animales intervienen consecutivamente para conseguir un determinado propósito. Así, en el relato Kuátí éde kléble yé julíta oáde gige ('El hombre que compraba animales') (Margery Peña y Rodríguez Atencio, 1992: 93 y ss.) se refiere un pasaje en el que varios animales intentan llegar a un barco para recuperar un objeto robado. En él, el intento del sapo se enuncia en los términos siguientes:

"Bodregá no móä begáble ieéru, giráwa joyáble blé galige, joyáble blé galige blé dega mịi joyáble buále alīị giti du jogeblébi oáñüama 'El sapo fue enviado primero, pero al llegar a la orilla del mar tuvo que detenerse porque el barco ya se encontraba lejos'.

\section{A su vez, en el relato Chibiá chuí dige} dái ('La madre del Sol y de la Luna') se halla un pasaje en el cual el Sol le pide consecutivamente a determinados animales que vayan a buscar agua para apagar el gran incendio. En el intento participan el sapo, el zopilote, el colibrí y la golondrina. La intervención del sapo se narra en los términos siguientes: 
"...jogéble joyáble blídega blé digé blé galige, joyáble blire jolênikabe, giti chigéble no mïï talininge '...fue, llegó a la orilla del mar, pero nada hizo allí sino comer, tras lo cual regresó'.

Si se cotejan estos enunciados con los comprendidos en los números 93-96 del relato, se perciben estrechas similitudes tanto en la expresión como en los contenidos de los tres pasajes.

Estas analogías nos conducen a postular que enfrentado a la narración del pasaje en el que distintas especies son enviadas a cumplir una determinada tarea, el informante incorporó en él de un modo consciente -o inconscientemente, llevado por el "ritmo alegretto" que caracteriza su "modus narrandi"- un elementoel sapo, en este caso -correspondiente a secuencias de un contenido similar pertenecientes a otros relatos, aun cuando su inclusión en el texto que aquí nos ocupa resulta contextualmente inapropiada por la alusión a "la orilla del mar" en el mito del arca.

Tratándose de un hecho que hemos percibido en varias de las narraciones que conforman el corpus que hasta la fecha hemos reunido, estamos a la espera de obtener relatos de otros informantes para determinar si estas "interpolaciones de correlatos" constituyen una característica de la narrativa oral del bocotá de Chiriquí, o bien si, por el contrario, se originan en la singularidad de nuestro informante.

\section{2. "Cuando se apagó la luz del sol en los primeros tiempos".}

El segundo, y a la vez el más breve de los cuatro relatos, desarrolla el difundido tema de "la larga noche". Sobre esta base, a los motivos comunes señalados en los inicios de estos comentarios, deben sumarse como específicos los indexados como A1046, "Eclipse mundial prolongado", y F965. "La oscuridad impenetrable".

Un hecho notorio en este relato lo constituye la omisión que en él se percibe de uno o varios pasajes, lo cual afecta la consecuencialidad de varios elementos de su contenido. En efecto, el mandato del gran cacique en rela- ción a que la gente construya un cerco alrededor de cada casa, queda, en virtud de esta omisión, sin justificación alguna en el desarrollo posterior del texto.

No obstante, considerando la referencia al "cerco" que el gran cacique ordena construir alrededor de cada casa, es posible conocer el contenido de los pasajes omitidos si acudimos a una versión guaymí de este mito recogida por Constenla Umaña (1982: 104). En efecto, en un pasaje de esta versión se lee:

"Entonces la gente se organizó para hacer una casa grande rodeada por una gran cerca por sus cuatro costados, porque al apagarse el sol iban a venir los diablos y otros espíritus. (...) Y en la casa rodeada por la cerca ninguno podía dormir. Al que se dormía lo arrastraban afuera los espíritus y alli lo devoraban. Todos podian oir como estaban devorando a quienes lograban sacar de la casa".

Tomando en cuenta que los guaymíes constituyen un pueblo con el que los bocotás de Chiriquí comparten, al margen de la territorialidad, muchos elementos de tradición cultural, resulta válido postular que el relato bocotá, haya tenido un desarrollo en gran medida análogo, el cual, por alguna razón, no se plasmó de manera completa en el texto en referencia.

\subsection{Koróyi Tóndo y Mési Tôndo}

El tercero de los relatos refiere el mito del gran temblor, el cual, como ya lo señaláramos, no se halla entre los más difundidos en la narrativa cataclismológica indoamericana.

Atendiendo al desarrollo de su motivo configurante -A1061. "Temblores en el fin del mundo" -el contenido del texto bocotá se estructura sobre la base de otros dos motivos, correspondientes éstos a los indexados en la obra de Stith Thompson como P251.5.4. "Dos hermanos contrastantes", en el cual se enmarca la oposición entre Koróyi Tóndo y Mési Tóndo, y B140. "Animales proféticos" -al cual se asocian en este relato los motivos B560. "Animales advierten al hombre" y B521. "Animales salvan de un peligro fatal"- relacionados estos últimos con la figura del mono congo (Ateles geoffroyi), cuya intervención ocupa un amplio sector del relato. 
Al margen de éstos, otros de condición relevante en el curso de la narración son los motivos F1041.1. "Muerte extraordinaria", Q280. "La inhumanidad castigada" y M370.1. "La profecía cumplida".

En lo que respecta a otros elementos de su contenido, uno de los aspectos de este relato que lo diferencian de los dos anteriores, pero que, no obstante, es relativamente frecuente en la tradición cataclismológica indoamericana, radica en el hecho de que la calamidad universal se origina en un conflicto que tiene lugar en el ámbito restringido de un núcleo familiar.

Sin embargo, la parte medular y más extensa del relato corresponde a la profecía de la figura omnisciente del mono congo y a su posterior cumplimiento en el cierre de la narración.

Lo básico de esta profecía se resuelve en tres acciones que deben cumplir Koróyi Tóndo y su gente para hacer que termine el cataclismo. Estas tres acciones son la petición de cacao por cuatro veces que Koróyi Tóndo le ha de hacer a su hermana; la muerte de Mési Tóndo, provocada al agitar junto a su cabeza las semillas de cacao contenidas en el puño, y, por último, su entierro con la cabeza hacia abajo.

Con respecto a la primera de estas acciones cabe anotar que el cuatro es la cifra mágica o cabalística de las culturas de genealogía chibcha. A su vez, en lo pertinente a la segunda acción, el acto de agitar con movimientos hacia arriba y hacia abajo semillas de cacao dentro del puño, guarda una estrecha similitud con el movimiento de estas semillas dentro de las maracas, instrumento que tiene una especial relevancia en muchas ceremonias del pueblo bocotá.

Finalmente, en lo relacionado con la acción de enterrar el cuerpo de la mujer con la cabeza hacia abajo, si bien no la asociamos con ninguna de las manifestaciones de la cultura bocotá que obran en nuestro conocimiento, ella presenta alguna analogía con elementos del mito del origen de los temblores que hemos encontrado en la tradición oral de otros pueblos del área. Así, en el relato paya "Leyenda del por qué tiembla la tierra" (Flores Mejía, Lázaro, 1989: 81-82) se narra la historia de nueve hermanos de los cuales uno era tan malo que el menor encargó a sus hijas que de una hebra de pelo hicieran una víbora para terminar con él. Luego que ésta lo mordió, el hombre le pidió a su sobrina que al morir sólo enterraran la mitad de su cuerpo, solicitud a la que la mujer se negó, consintiendo en dejarle afuera sólo el dedo meñique, el cual, hasta el día de hoy, el hombre mueve haciendo que tiemble la tierra.

Por su parte, la narración guaymí "Origen del temblor de tierra" (Guardia, ms.) contiene un episodio -análogo al de la versión en esta lengua de "La madre del Sol y de la Luna", pero referido en este caso al citado mito- en el que un hombre y los suquias resuelven para acallar los lamentos de la madre de aquel, confinarla en un profundo hueco, lugar donde ella, al golpear las paredes, origina desde entonces los temblores que estremecen la tierra.

Al margen de estas asociaciones que hemos planteado en relación con elementos contenidos en las acciones profetizadas por el mono congo, cabe señalar que no hemos encontrado en otros textos de la tradición oral bocotá algún dato referente a la costumbre de portar en el cuello una sarta de semillas de cacao como signo de sumisión o de arrepentimiento, tal como lo hace uno de los personajes en este relato.

\subsection{Bogá Dadiá y Nuí Dadiá}

El cuarto y último de los relatos se refiere al mito de la gran hambruna, el cual -al igual que el mito del gran temblor- tampoco constituye uno de los más difundidos en la tradición oral indoamericana.

En relación con los anteriores, este relato ofrece un planteamiento algo distinto en la medida en que a los motivos A1003. "La calamidad como castigo por faltas" y D2096. "Pudrición mágica de los alimentos" se une con una funcionalidad también estructurante el 
motivo Z210. "Los hermanos héroes", el cual se implementa con el motivo F577.2. "Hermanos idénticos en su apariencia", hecho este último que es relevante en el texto dado que la característica de ser "pequeñitos y feos" es la que motiva su desprecio por parte de los habitantes del lugar.

En estas circunstancias, el castigo consistente en la pudrición de las semillas y de las cosechas da origen a la gran hambruna que extermina a una gran parte de la humanidad.

Cabe aquí hacer presente que en los textos de la mitología cataclismológica especialmente sudamericana, se da con relativa frecuencia un elemento análogo al contenido en este relato, cual es el que un conflicto enmarcado en un ámbito local -familiar o, a lo sumo, tribal- proyecta sus consecuencias a un espacio de tal amplitud que abarca a toda la humanidad.

Al margen de estos elementos, cabe anotar con respecto a este relato otros dos de interés. El primero de ellos se relaciona con el hecho de que al resolverse ambos hermanos a repartir las semillas para terminar con el flagelo, la narración incorpora el motivo A1425. "El origen de las semillas", dado que el texto especifica: Chudé amạăt klé dabá ('Son éstas las semillas que están en la tierra'). El segundo elemento consiste en que la pudrición mágica se origina en el marco de una ceremonia autóctona bocotá, cual es la denominada "velación del cacao" (véase la nota 14).

\section{Notas}

1. Sobre los fundamentos y equivalencias de este alfabeto práctico, véase Margery Peña "El origen del mundo en una narración bocotá de Chiriquí". Estudios de Lingüística Chibcha VIII, 1989, nota 3 , así como "Cuatro relatos mitológicos bocotás de los yé nansére ('seres malos')". Revista de Filología y Lingüistica de la Universidad de Costa Rica XV, 2, 1989, nota 7. También Margery Peña y Rodríguez Atencio, 1992: 9-10.

2. Cabe señalar que en el bocotá de Chiriquí -carecemos de la información correspondiente al dialecto de Veraguas- el término júli significa propiamente 'huérfano', lo cual concuerda en el marco de este relato con la importancia que los individuos de esta condición poseen, al igual que los primogéticos, tanto en la tradición cultural como en las ceremonias de este pueblo (confróntese, al respecto, el cuarto de los relatos aquí presentados). No obstante, tanto en la traducción palabra a palabra como en la versión libre de este primer texto, hemos optado por considerar este término como denotante del nombre propio del personaje del relato.

3. En la fonología del bocotá de Chiriquí, los fonemas oclusivos dentoalveolares sordo $(V /)$ y sonoro $(/ \mathrm{d} /)$ alternan libremente en posición intervocálica. A su vez, los fonemas oclusivos velares sordo $(/ \mathrm{k} /$ y sonoro $(\mathrm{g} / \mathrm{h}$ se manifiestan en variación libre en posición inicial seguidos de vocal oral, o bien seguidos de la consonante lateral (/1/) más vocal oral. En el alfabeto práctico, estas variaciones se reflejan en las alternancias de formas como gíti-gidi 'entonces', báte báde 'golpear', batá. gli badágli 'último', ke ge 'dat', kóde góde 'por', klé glé 'estar', etc.

4. El término kiru significa 'noticia', 'aviso', así como 'acontecimiento importante'. En este último marco referencial, kíru denota también 'cataclismo', 'desastre', 'calamidad'. De acuerdo con estos significados, hemos procedido en este relato a traducir el término según los respectivos contextos.

5. El término kuäï denota tanto el genérico 'persona' y el colectivo 'gente', como el específico 'hombre'. Cabe sí anotar que en su denotación específica de 'hombre', este término alterna con la expresión kuảï blâle, aunque esta última registra una bajisima frecuencia.

6. El término bitigá significa primariamente 'familia', tanto en sus dimensiones de 'familia nuclear' como de 'familia extensa'. No obstante, el término se suele emplear con el significado de 'pueblo', con una referencialidad propiamente étnica. En estos relatos hemos procedido a traducir el término con el significado impuesto por los respectivos contextos.

7. El término kiruá significa 'hijo' o 'hijos varones'. Su denotación plural fue manifestada en este caso por el propio informante. Un caso similar se presenta en relación con el término jiá, que posee los significados de 'hija' o 'hijas' y el cual aparece en el enunciado siguiente.

8. El verbo bége significa 'poner', 'colocar' y, en contextos como éste y como muchos otros en estos relatos, 'poner atención', 'prestar atención'.

9. El término bá denota en el bocotá de Chiriquí tanto la segunda persona singular ('tú', 'usted') como la segunda persona plural ('ustedes'), no pudiéndose en el caso de este último significado -a diferencia de lo que ocurre con la primera y tercera personas del plural- acudirse a posponerle el pluralizador "-dre" (la forma *bádre es agramatical).

En los casos de una significación específica puede emplearse el pronombre seguido por un cuantificador, el cual se constituye por la forma que corresponde al género humano -kui(a)- seguida del radical numeral respectivo. Así, por ejemplo: bá kuióm 'ustedes dos', bá kuiamål 'ustedes tres" (Cfr. Solis Hernández: 1989: 9-10). 
En lo que se refiere a los textos aquí presentados, hemos traducido este término según los respectivos contextos.

10. El término judén̈ 'zopilote' es de procedencia guaymí. Por esta razón su transcripción en el alfabeto práctico contraviene la regla de que la nasal posnuclear fonética sólo sigue a vocales nasales.

11. En esta secuencia del relato se hace mención de cuatro actividades colectivas características, entre otras, de la cultura bocotá, a saber: "chichadas", "peonadas", "balserías" y "ceremonias de esclarecimiento". Las "chichadas" -comunes a todos los pueblos del área- son reuniones ocasionales donde se consumen bebidas fermentadas en medio de cantos y bailes. En lo que respecta a las "peonadas", nuestro informante concordó con Torres de Araúz (1980: 306) al describirlas como determinadas actividades de trabajo comunal, tales como "limpiar" el monte, realizar una siembra en conjunto, construir una casa, etc., que terminan por lo general con una celebración festiva del acontecimiento. Con respecto a las "balserías" debe señalarse que éstas eran comunes a guaymies y bocotás hasta que hace ya años fueron prohibidas por las autoridades civiles. La "balsería" era una competencia en la que intervenían dos grupos que se alineaban frente a frente a una distancia aproximada de veinte pasos y provisto cada participante de palos hechos de madera de balsa. La competencia consistía en arrojar los palos a las pantorrillas o pies de los adversarios con el fin de hacerlos caer. Al parecer, las dos reglas básicas de la balsería eran, en primer lugar, que cada competidor tenía derecho a diez tiros, y, en segundo lugar, que se prohibían -y eran considerados como una provocación- los golpes dados más arriba de las rodillas. Torres de Aráuz (id.:307) apunta al respecto que a diferencia de los bocotás, en las balserías guaymíes se enfrentaban sólo dos competidores (véase también Santo Tomás, 1965:81-82).

No obstante, en lo que respecta a las "ceremonias de esclarecimiento", no hemos encontrado referencias entre los descriptores de las ceremonias bocotás.

Consultado sobre estas "ceremonias de esclarecimiento", nuestro informante señaló que ellas eran "reuniones de no más de veinte personas en las que se esclarecian hechos delictivos y se castigaba a los culpables". En una descripción más amplia, especificó que estas ceremonias -en las que sólo participaban varones -se hacían siempre de noche y en sitios apartados. La actividad era presidida por el rugún̈, personaje de la comunidad que tenía esta función específica y que, en tal condición, convocaba a los acusados de un asesinato, un robo, una agresión, etc., y, junto con ellos, a los robóbi, que eran los testigos que hablaban en contra o a favor del acusado. Un aspecto de interés señalado por nuestro informante fue que durante toda la ceremonia, dos nativos, hacían sonar incesantemente el bubé 'palo zumbador' o 'zumbadera' por sobre las cabezas de los participantes. Al finalizar el juaīñ, el rugúnï. declaraba, según su convicción, la inocencia o la culpabilidad del acusado, y, en el último de estos casos, ordenaba el castigo que, según la gravedad de la falta, podía ir desde una azotaina hasta la muerte.

Un aspecto sobre el que nuestro informante insistió durante su descripción fue el relacionado con el hecho de que las "ceremonias de esclarecimiento "eran propiamente bocotás, aunque también las practicaban los guaymíes". Finalmente y cerrando sus comentarios, nos señaló que desde hace mucho tiempo las "ceremonias de esclarecimiento" ya no se realizan pues ellas fueron prohibidas por las autoridades panameñas.

12. Esta forma, de uso frecuente, resulta de la contracción de los términos mïa 'no' y ialle 'no haber'.

13. Uno de los ámbitos más compejos de la morfología del bocotá de Chiriquí, por la concurrencia de formas supletivas y, en no pocos casos, sincréticas, lo constituye la flexión de los pronombres personales en determinadas frases posposicionales. Así, por ejemplo, los pronombres de tercera persona singular (cheemáña) y plural (cheemañáadre) presentan la forma ó cuando integran una frase constituida por la posposición comitativa gulé, v. gr.:

¡iá no kléble tuí ó gule

hija(s) gen estar-rem vivir él con

'Sus hijas vivían con él'

En lo que respecta a la forma món, que motiva esta nota, ella corresponde a la segunda persona plural en frases constituidas por la posposición dativa ke ge. A las complejidades señaladas se suma el hecho de que en este caso la flexión pronominal es homónima de las formas refleja y recíproca.

14. La ceremonia referida en este pasaje muestra una estrecha analogía con la que en su investigación sobre etnografía bocotá, Herrera y González (1964:79-80) denominan "velación del cacao". La descripción que de ella hacen ambos autores es la siguiente:

"Para propiciar las cosechas, cuatro días antes o un dia, al escogido para plantar las semillas, "velan" muestras de los productos. Esto se hace después de levantar una cruz en el terreno. Alrededor de ésta se colocan los productos. Se queman, para ahumar, sustancias resinosas como el "chutra", la caraña, ajies picantes y todo ello se coloca sobre un panal de comején. Los encargados de quemar todo esto son dos niños, mellizos si los hay, o si no, el mayor y el menor de una familia cualquiera. Se prepara una solución con hojas de la planta llamada mastranto y se esparce sobre las semillas con ramas de la misma planta. Grandes recipientes con bebidas de cacao son repartidas entre los asistentes que deben estar sentados formando una cruz, alrededor del sahumario. El cacao debe ser de la primera cosecha. Esta ceremonia dura varias noches y es conocida con el nombre de "velación del cacao" (...). Además, el indio coloca varias semillas en forma de cruz en el terreno y las cubre con tierra para ahuyentar las plagas de los sembrados. Cuando las semillas germinan, el terreno ya está "curado" y puede procederse, entonces, a efectuar la roza". 
En lo que respecta a nuestro informante -y considerando que su procedencia es distinta del área comprendida en la investigación de los dos autores citados- éste nos refirió la ceremonia con algunas variantes en relación con la descripción recién anotada. Según nuestro informante, quince días antes de iniciar una siembra o la construcción de una casa, un primogénito o, en su defecto, un huérfano, procede a colocar cuatro cruces pequeñas en los cuatro puntos cardinales del sitio, para luego, y en el medio de aquel espacio, levantar una cruz más alta, junto a la cual se quema un nido de comejenes. Cuando éste ya ha sido consumido por el fuego, el primogénito -o el huérfano- bebe en el sitio cacao de la primera cosecha, el cual después se reparte generosamente entre todos los asistentes. En el caso de las siembras, la ceremonia tiene por objeto preservarlas de plagas y asegurar un buen crecimiento de la plantación. En lo que respecta a la construcción de las casas, el propósito es que sus moradores gocen de buena salud y prosperidad. Finalmente debemos acotar que al inicio y al final de esta descripción, el informante nos señaló que ésta es una costumbre propia de los bocotás "que los guaymíes después imitaron y la siguen haciendo en la actualidad".

15. En el Apéndice de este artículo hemos procedido a enumerar, de acuerdo con la clasificación del Motif Index de Stith Thompson, los motivos contenidos en cada uno de estos cuatro relatos.

\section{Bibliografia}

Amodio, Emanuele. 1989. "La mitología sincrética makuxi. Textos, análisis, perspectivas". En Las religiones amerindias 500 años después, Abya-Yala Editores. Quito: Abya-Yala (Colección 500 años, No 4), 91-136.

Boremanse, Didier. 1989. "Ortogénesis en la literatura maya lacandona". Mesoamérica 17, 61-104.

Constenla Umaña, Adolfo. 1982. "Seis narraciones tradicionales guaimíes (moves)". Revista de Filología y Lingüistica de la Universidad de Costa Rica 8, Números 1 y 2, 103-107.

Fischer, Manuela y Konrad Th. Preuss. 1989. Mitos kogui. Quito: Abya-Yala (Colección 500 Años, № 20).
Flores Mejía, Lázaro. 1989. Mitos, Leyendas y Ritos de los Pech. Tegucigalpa: Producciones Audiovisuales Educativas de Honduras.

Guardia, Nisla. "Origen del temblor de tierra". Ms.

Herrera, Francisco A. y Raúl González. 1964. "Informe de una investigación etnográfica entre los indios de Bocas del Toro (1964)". Hombre y Cultura (Panamá), I, 3, 56-81.

Krickeberg, Walter. 1928. Mitos y Leyendas de los aztecas, incas, mayas y muiscas. México: Fondo de Cultura Económica, 3ªimpresión, 1985.

Lara, Jesús. 1973. Mitos, leyendas y cuentos de los quechuas. Antología. La PazCochabamba: Editorial Los Amigos del Libro.

Margery Peña, Enrique. 1990. "La leyenda de "la madre del Sol y de la Luna" en una versión guaymí y en una versión del bocotá de Chiriquí". En Selected Papers from the VII International Symposium on Latin American Indian Literatures. Mary H. Preuss Editor. Culver City: Labyrinthos, 23-42.

Margery Peña, Enrique y Francisco Rodríguez Atencio. 1992. Narraciones Bocotás (Dialecto de Chiriqui). San José: Editorial de la Universidad de Costa Rica.

Montejo, Víctor D. 1985. "Cuentos tradicionales de Jacaltenango". Mesoamérica 10, 411420 .

Rowe, John Howland. 1946. "Inca Culture at the Time of the Spanish Conquest". En Handbook of South American Indians. Vol.2. The Andean Civilizations, Julian H. Stewart Editor. Washington: 
Smithsonian Institution. Bureau of American Ethnology. Bulletin 143, 183-330.

Santo Tomás, Fray Adrián de. 1965. "Conquista de la Provincia de Guaymí, por el venerable padre Maestro Fr. Adrián de Ufeldre, en el Reino de Tierra Firme". Hombre y Cultura (Panamá) I, 4, 72-121.

Schultze Jena, Leonhard. 1935. Mitos y leyendas de los pipiles de Izalco. San Salvador: Ediciones Cuscatlán, 1977.

Solís Hernández, Mayra. 1989. "La frase nominal en el bocotá de Chiriquí". Universidad de Costa Rica: Tesis de Licenciatura en Lingüística.

Thompson, Stith. 1955-1958. Motif Index of Folk Literature. 6 Vols. Bloomington: Indiana University Press.

Torres de Aráuz, Reina. 1980. Panamá Indigena. Panamá: Instituto Nacional de Cultura.

Uggé, Enrique. 1991. Mitología sateré-maué. Quito: Abya-Yala (Colección 500 Años, No 34).

Wilbert, Johannes y Karin Simoneau (Editores). 1983. Folk Literature of the Bororo Indians. Los Angeles: UCLA Latin American Center Publications.

Wilbert, Johannes y Karin Simoneau (Editores). 1988. Folk Literature of the Mocovi Indians. Los Angeles: UCLA Latin American Center Publications.

\section{Apéndice}

Por considerarla de utilidad, especialmente para propósitos comparativos, hemos incorporado en este Apéndice una lista de los motivos contenidos en cada uno de los relatos. La clasificación y denominación de éstos la hemos hecho de acuerdo con el Motif Index, de Stith Thompson.

Debemos sí anotar al respecto que en el caso de las denominaciones, hemos procedido a consignarlas en español. En lo que respecta al signo más (+) que se agrega a determinadas clasificaciones, su uso sigue al análogo y adecuado recurso empleado por Wilbert y Simoneau, e identifica aquí los motivos cuyo contenido requiere de una ampliación de acuerdo con el contexto narrativo bocotá.

1). Júli ke kíru suadâble Chubé nọ ('El cataclismo que Chubé le anunció a Júli')

A182.3. Dios le habla a un mortal

A1003. Calamidad como castigo por faltas

A1005. Preservación de la vida durante una calamidad mundial

A1010. Diluvio

A1015. Inundación causada por dioses u otros seres superiores

A1018. Inundación como castigo

A1021. Diluvio: escape en un barco (arca)

A1021.1. Parejas de animales en el arca

A1021.2. Pájaros exploradores enviados fuera del arca

A1316.6.+ Origen de los dientes

A2291. Características de animales adquiridas durante el diluvio

D470.+ Transformación: cambio del material de un objeto

D683.5.+ Transformación por dioses

Q150. La inmunidad en el desastre como recompensa

Q411. La muerte como castigo

Q420. Castigo: ahogamiento

2) Chui chará drebadáble niạain ('Cuando se apagó la luz del sol en los primeros tiempos')

A1003. Calamidad como castigo por faltas A1005. Preservación de la vida durante una calamidad mundial 
A1046. Eclipse prolongado de sol

F965. Oscuridad impenetrable

Q150. La inmunidad en el desastre como recompensa

Q411. La muerte como castigo

3). Koróyi Tóndo Mési Tóndo ('Koróyi Tóndo y Mési Tóndo')

A1003. Calamidad como castigo por faltas

A1005. Preservación de la vida durante una calamidad mundial

A1061.1.+ Temblores en el fin del mundo

B140. Animales proféticos

B520. Animales salvan la vida de personas

B521. Animales salvan de un peligro mortal

B560. Animales advierten al hombre

F1041.1.+ Muerte extraordinaria

M370.1.+ La profecía cumplida
P251.5.4. Dos hermanos contrastantes

Q150. La inmunidad en el desastre como recompensa

Q280. La inhumanidad castigada

Q411. La muerte como castigo

Q552.25 El temblor como castigo

\section{4) Bogá Dadiá Nuí Dadiá ('Bogá Dadiá y Nüi Dadiá')}

A1003. Calamidad como castigo por faltas

A1005. Preservación de la vida durante una calamidad mundial

A1425.+ Origen de las semillas

D2096. Pudrición mágica

D2143.1. Lluvia producida por magia

F577.2. Hermanos idénticos en su aspecto

F962. Lluvia extraordinaria

Q280. La inhumanidad castigada

Q411. La muerte como castigo

Z210. Los hermanos héroes 